\title{
Multiplex Nucleic Acid Assay of SARS-CoV-2 via a Lanthanide Nanoparticle-Tagging Strategy
}

\author{
Ziyan Li, Xue Chen, Zili Huang, Jing Zhou, Rui Liu,* and Yi Lv*
}

Cite This: Anal. Chem. 2021, 93, 12714-12722

Read Online

ABSTRACT: Early diagnosis, early isolation, and early treatment are efficient solutions to control the COVID-19 pandemic. To achieve the accurate early diagnosis of SARS-CoV-2, a multiplex detection strategy is required for the cross-validation to solve the problem of "false negative" of the existing gold standard assay. Here, we present a multicomponent nucleic acid assay platform for SARS-CoV-2 detection based on lanthanide nanoparticle (LnNP)tagging strategy. For targeting SARS-CoV-2's RNA fragments ORFlab gene, RdRp gene, and E gene, three LnNP probes can be used simultaneously to identify three sites in one sample through elemental mass spectrometry detection with limits of detection of $1.2,1.3$, and $1.3 \mathrm{fmol}$, respectively. With the multisite crossvalidation, we envision that this multiplex and sensitive detection platform may provide an effective strategy for SARS-CoV-2 fast screening with a high accuracy.

$\mathrm{T}$ he pandemic of novel coronavirus disease (COVID-19) ${ }^{1}$ by severe acute respiratory syndrome coronavirus 2 (SARS-CoV-2) has led to a surge of a series of serious public health, medical, and society issues. Early diagnosis, early isolation, and early treatment are efficient solutions to control the COVID-19 pandemic. As one of the diagnostic criteria, computerized tomography images can only provide a diagnosis accuracy of $76.4 \%$. $^{2}$ Antibody-based serological tests are not suitable for the early diagnosis ${ }^{3,4}$ because they are not produced until 3 weeks after infection. ${ }^{5}$ The two currently used nucleic acid pathogenic diagnoses are nucleic acid sequencing and nucleic acid fluorescence quantitative polymerase chain reaction (qPCR). ${ }^{6}$ Nucleic acid sequencing is relatively time-consuming and expensive. ${ }^{7}$ As the current gold standard, qPCR falls in a dilemma of "false negative". 8,9 Up to 20 to $67 \%$ of patients are tested positive only after multiple repeated tests, ${ }^{10}$ as also described in National Health Commission of China's new coronavirus pneumonia diagnosis and treatment plan. ${ }^{11}$

To achieve the accurate diagnosis of SARS-CoV-2, a multiplexed detection strategy is required for multiple characteristic-related markers for the cross-validation. The U.S. Centers for Disease Control (CDC) gives examples of recommended gene selection and multicomponent testing methods. ${ }^{12}$ World Health Organization (WHO) recommends three qPCR reactions to confirm COVID-19 infection, while a total of 3 qPCR tests were performed sequentially for each patient sample. ${ }^{13}$ Besides, electrochemical biosensors, ${ }^{14}$ colorimetric sensors, ${ }^{15}$ a loop-mediated isothermal amplification (LAMP) combined with clustered regularly interspaced short palindromic repeats (CRISPER) system, ${ }^{16,17}$ microfluidic assay, ${ }^{6}$ and point-of-care testing (POCT) platforms $^{18}$ have been developed for single or multicomponent detection. ${ }^{19-23}$ Despite great success, ${ }^{24}$ these optical and electrochemical strategies are practically limited by spectral overlap-caused interference for the simultaneous multicomponent detection. ${ }^{25}$

Elemental mass spectrometry, especially inductively coupled plasma mass spectrometry (ICPMS), ${ }^{26-28}$ is emerging as a powerful platform for the multiplex bioassay ${ }^{29-31}$ due to its high sensitivity, ${ }^{32}$ wide dynamic range, ${ }^{33}$ and multiplex sensing ability. ${ }^{34-36}$ The multiplex bioassay by ICPMS ${ }^{37}$ possesses many superiorities, such as a low sample consumption, ${ }^{38}$ a short analysis time, a simplified procedure, and a low cost. ${ }^{38-40}$ Zhang's group developed a multiplex nucleic acid assay and immunoassay by lanthanide macrocyclic compound tagging. ${ }^{41,42}$ Wang et al. performed a multiplex assay for protease markers. ${ }^{43}$ Simultaneous detection of multiple microRNAs by the MNAzyme-catalyzed amplification assay was realized, ${ }^{44}$ while single-particle mode ICPMS was applied for a threecomponent homogeneous immunoassay of pancreatic cancer. $^{45}$ Multicomponent marker and disease subtype analysis provides the possibility of the cross-validation through a

Received: June 24, 2021

Published: September 8, 2021 


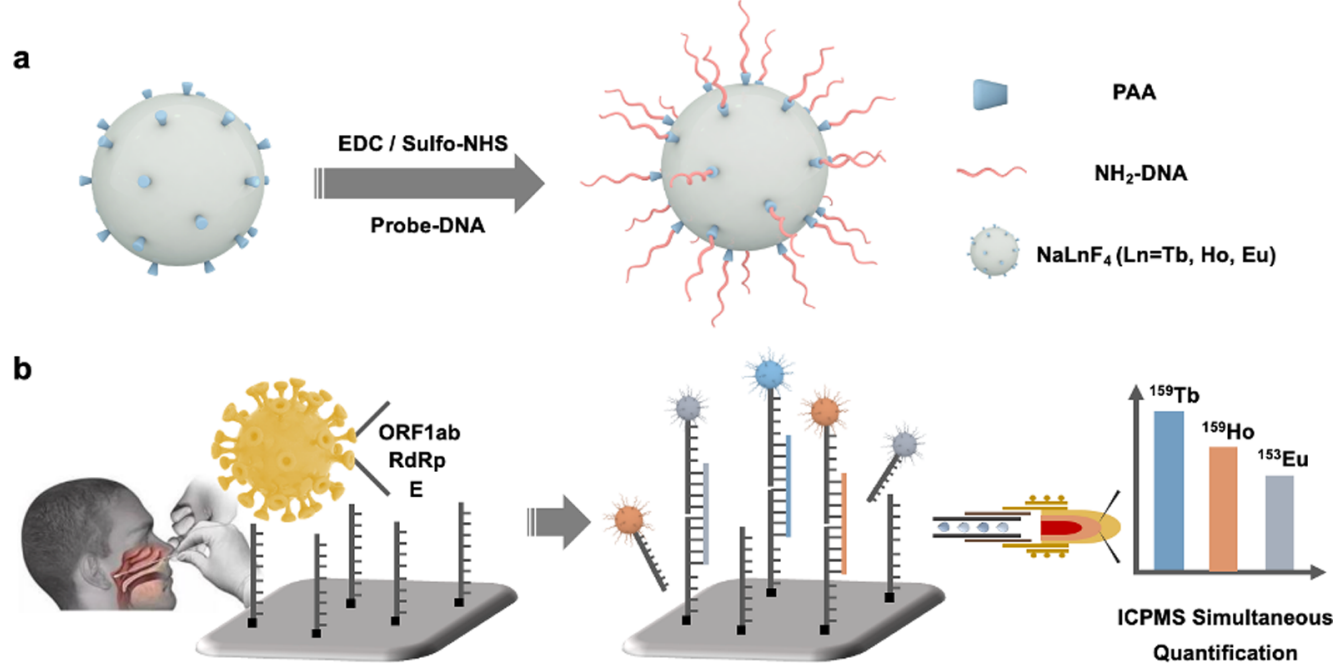

Figure 1. (a) Schematic illustration of the functionalization of $\mathrm{NaLnF}_{4} \mathrm{NPs}(\mathrm{Ln}=\mathrm{Tb}, \mathrm{Ho}$, and Eu). PAA-coated NPs were obtained by one-pot solvent thermal preparation to facilitate further conjugation with $\mathrm{NH}_{2}$-functionalized capture DNA to form a capture probe. (b) Schematic illustration of the multiplexed assay process. RNA fragments ORF1ab, RdRp, and E were anchored on the MBs by interacting with capture DNA attached to MBs and labeled with $\mathrm{NaLnF}_{4} \mathrm{NP}$-probe DNA, which allows the ultrasensitive ICPMS detection of the dissolute $\mathrm{Ln}^{3+}$-chelates.

simultaneous monitoring of multiple parameters, ${ }^{46}$ which plays a significant role in improving the accuracy of the disease diagnosis. However, the existing assay formats are not compatible with the direct detection of SARS-CoV-2, which is mainly limited by the low sensitivity of macrocyclic compound element labels.

Herein, we proposed a multiplexed nucleic acid assay for improving the detection rate of SARS-CoV-2 via lanthanide nanoparticle (NP)-tagging strategy. Three lanthanide NP (LnNPs, $\mathrm{Ln}=\mathrm{Tb}$, Ho, and Eu)-based nanoprobes were designed and applied to detect SARS-CoV-2's ORF1ab gene, RdRp gene, and E gene. Three kinds of capture DNA attached to magnetic beads (MBs) could hybridize with corresponding targets, and the half remaining chain could also hybridize with the as-prepared probe DNA-modified NPs. LnNP tags were digested in the enhancer solution and released lanthanide ions from NPs to those of the $\beta$-NTA- $\mathrm{Tb}^{3+} / \mathrm{Ho}^{3+} / \mathrm{Eu}^{3+}-\mathrm{TOPO}$ complex. $^{47}$ The LnNPs are ideal multiplex labels ${ }^{48}$ because lanthanides are numerous and similar in nature, ${ }^{49}$ and there are 55 to 64 atoms exist per $\mathrm{nm}^{-3} \mathrm{NP} .{ }^{50}$ Thanks to multiatoms inside each NP, a high sensitivity is obtained without the need of complex nucleic acid amplification procedures.

\section{EXPERIMENTAL SECTION}

Apparatus and Reagents. A PerkinElmer NexION 350 inductively coupled plasma mass spectrometer was used to detect ${ }^{153} \mathrm{Eu},{ }^{159} \mathrm{~Tb}$, and ${ }^{165} \mathrm{Ho}$ in standard mode. The operating conditions are listed in Table S1. Apparatus for characterization and detection is provided in the Supporting Information. Other details about reagents and materials used are also provided in it. DNA and RNA sequences used in this work are also listed in Table S2, Supporting Information.

Synthesis of $-\mathrm{COOH}-F u n c t i o n a l i z e d \mathrm{NaLnF}_{4}$ (Ln = ${ }^{153} \mathrm{Eu},{ }^{159} \mathrm{~Tb}$, and ${ }^{165} \mathrm{Ho}$ ) NPs. Carboxylic acid-functionalized $\mathrm{NaLnF}_{4}\left(\mathrm{Ln}={ }^{153} \mathrm{Eu},{ }^{159} \mathrm{~Tb}\right.$, and $\left.{ }^{165} \mathrm{Ho}\right) \mathrm{NPs}$ were synthesized as bioprobes adopting a one-step solvothermal route by employing polyacrylic acid (PAA) as the surfactant and a capping ligand, both of which provide excess $-\mathrm{COOH}$ for further bioconjugation and improving NPs' hydrophilicity (Figure 1a). Details are given in the Supporting Information.
Preparation of Probe DNA-NaLnF 4 NPs (O/R/E-Tb/Ho/ Eu NPs). To prepare probe $\mathrm{DNA}-\mathrm{NaLnF}_{4} \mathrm{NPs}$ as a signal reporter, $\mathrm{NH}_{2}$-modified probe DNA was directly attached with the $-\mathrm{COOH}$ group coating on the $\mathrm{NaLnF}_{4}$ surface through the EDC-NHS (N-ethyl- $N^{\prime}$-(3-(dimethyl-amino)propyl)carbodiimide- $N$-hydroxy succinimide)reaction. Specific details of the labeling process are given in the Supporting Information. After ligation, NPs were blocked with $2 \%$ bovine serum albumin (BSA) in TBS buffer to prevent protein's nonspecific binding and the residue carboxylic acid groups were blocked with excess tris in TBS buffer. Subsequently, the as-prepared probe DNA-NaLnF 4 NPs were diluted to $1.8 \mathrm{~mL}$ per OD DNA and made ready to use.

Preparation of Capture DNA-MBs (Capture O/R/E$M B)$. The process of attaching oligonucleotides on $\mathrm{MBs}$ was carried out according to the instructions of Dynabeads M-280. Ahead of all, pretreatment to avoid RNase contamination for RNA manipulation was performed, then biotinylated capture DNA was immobilized, specific details are given in Supporting Information. Following that the MBs with 2\% BSA were blocked to prevent nonspecific binding, and the DNA-coated MBs were redispersed in $100 \mu \mathrm{L}$ Tris- $\mathrm{HCl}$ buffer stored at 4 ${ }^{\circ} \mathrm{C}$ for further use.

Analysis of ORF1ab by Sandwich Assay-ICPMS. Before multicomponent RNA fragment detection, the feasibility and conditions of a single component assay were surveyed by utilizing ORF1ab as a model SARS-CoV-2 positive gene. To fulfill it, a certain amount of capture O-MBs was used for each sample with blocking ahead, 0 and 2 pmol ORF1ab were added under different conditions. Subsequently, probe O-

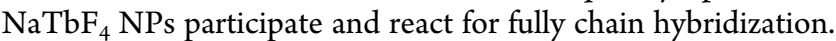
After the reaction is completed, $200 \mu \mathrm{L}$ enhancer solution was utilized to release ions from the formed structure for ICPMS quantification.

Simultaneous Analysis of ORF1ab/RdRp/E by Sandwich Assay-ICPMS. The RNA sandwich hybridization system was $7.5 \mu \mathrm{L}$ capture DNA-MBs. Because of the specific recognition between capture $\mathrm{O} / \mathrm{R} / \mathrm{E}-\mathrm{MB}$, targets $\mathrm{O} / \mathrm{R} / \mathrm{E}$, and probe $\mathrm{DNA}-\mathrm{NaLnF}_{4} \mathrm{NPs}(\mathrm{O} / \mathrm{R} / \mathrm{E}-\mathrm{Tb} / \mathrm{Ho} / \mathrm{Eu} \mathrm{NPs})$, a sandwich-like structure was formed with $\mathrm{MBs}$ as both solid- 


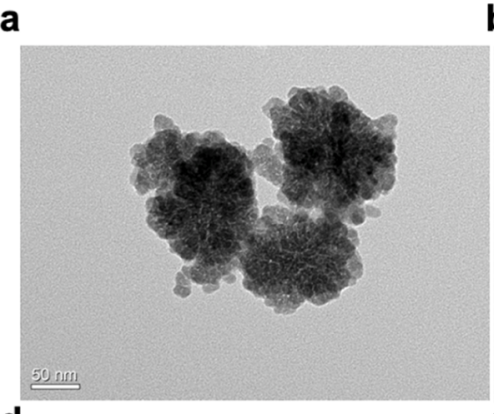

d

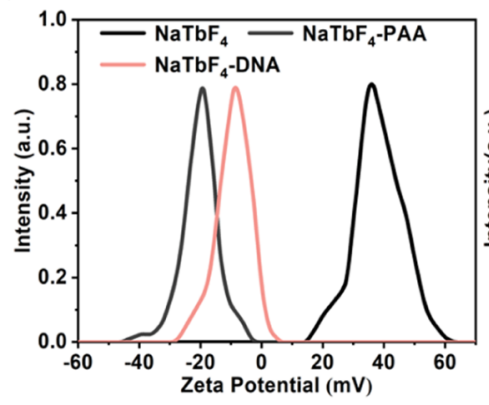

b

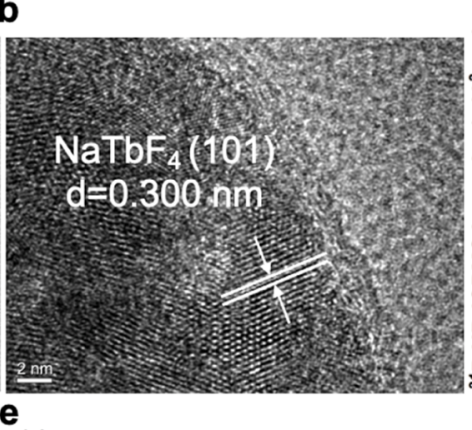

$\mathbf{e}_{1.0}$

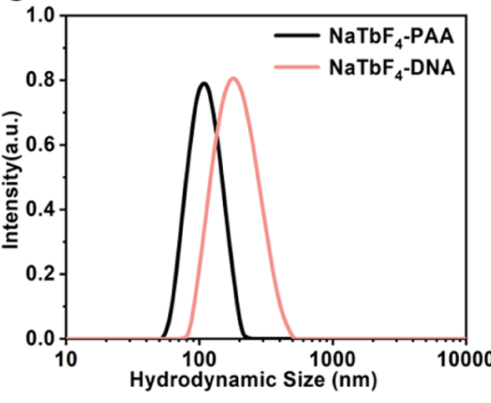

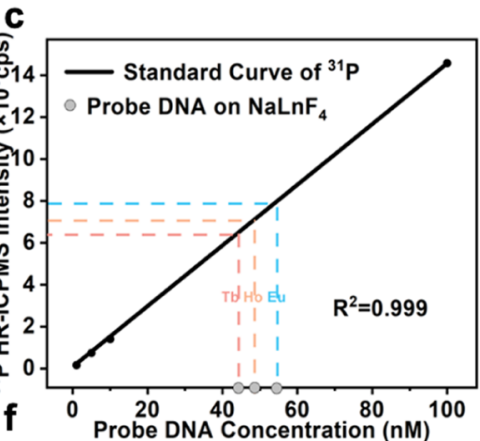

Probe DNA Concentration $(\mathrm{nM})$

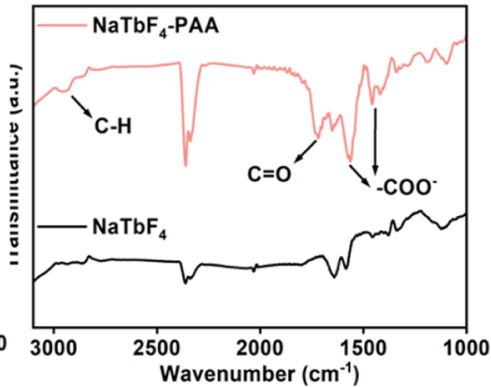

Figure 2. (a) TEM image of the as-prepared $\mathrm{NaTbF}_{4}-\mathrm{PAA}$. (b) HR-TEM image of $\mathrm{NaTbF}_{4}-\mathrm{PAA}$. (c) Quantification of probe DNA concentration with inner label ${ }^{31} \mathrm{P}$ in each sample detected by HR-ICPMS. (d) Zeta potential of naked $\mathrm{NaTbF}_{4}, \mathrm{NaTbF}_{4}-\mathrm{PAA}_{\text {, and NaTbF}}-\mathrm{DNA}$. (e) Particle size distribution of naked $\mathrm{NaTbF}_{4}, \mathrm{NaTbF}_{4}-\mathrm{PAA}$, and $\mathrm{NaTbF}_{4}-\mathrm{DNA}$. (f) FTIR spectra of the naked $\mathrm{NaTbF}_{4}$ and $\mathrm{NaTbF}_{4}-\mathrm{PAA}$ Feature peaks of the functional groups are marked.
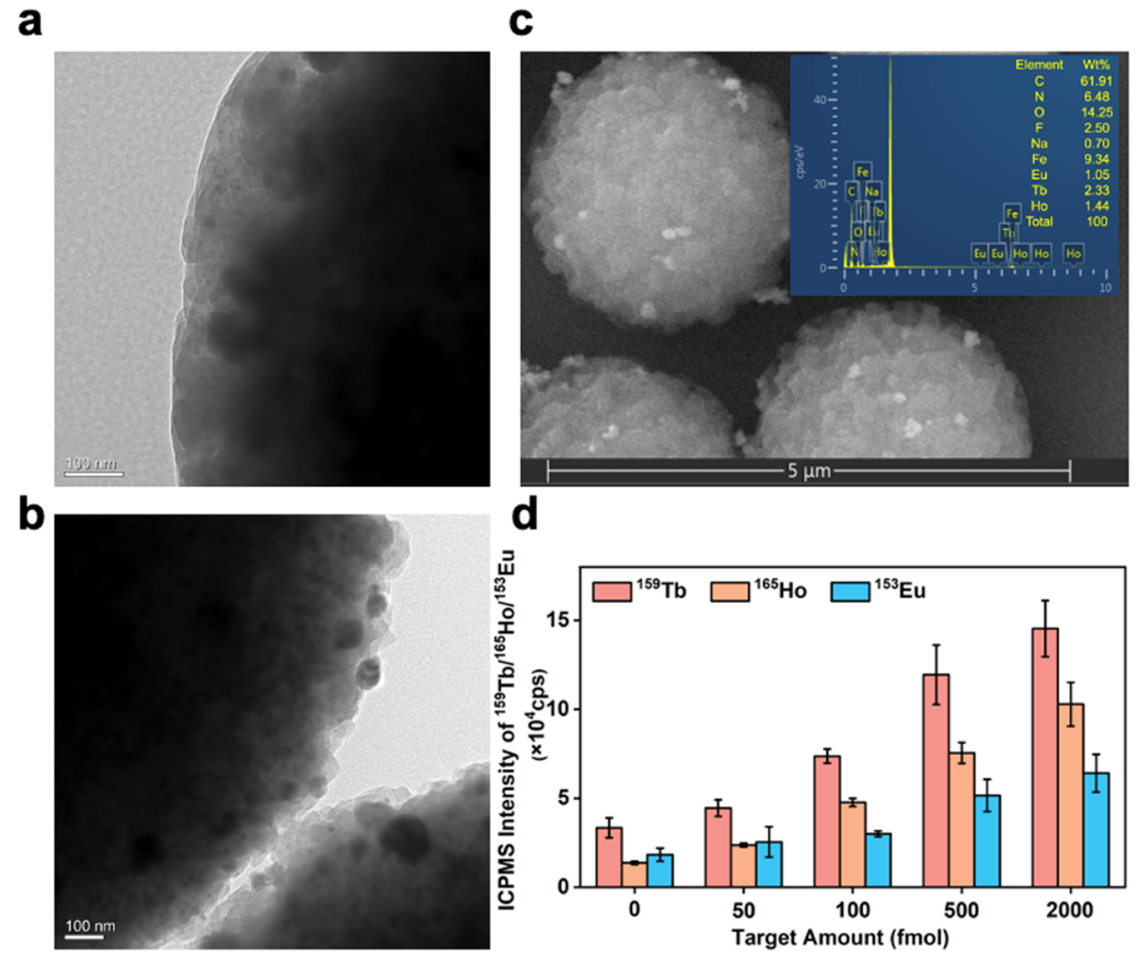

Figure 3. TEM of (a) naked MBs, (b) as-synthesized $\mathrm{NaTbF}_{4}, \mathrm{NaHoF}_{4}$, and $\mathrm{NaEuF}_{4} \mathrm{NPs}$ attached on $\mathrm{MBs}$ after hybridization. (c) SEM and EDS spectrum of the as-synthesized $\mathrm{NaTbF}_{4}, \mathrm{NaHoF}_{4}$, and $\mathrm{NaEuF}_{4} \mathrm{NPs}$ attached on MBs after hybridization. (d) Multiplex RNA fragment assay based on ICPMS. ORF1ab, RdRp, and E were simultaneously analyzed with different concentrations $(0,50,100,500$, and $2000 \mathrm{fmol})$.

phase reaction matrix and separation platform. Release of $\mathrm{Tb}^{3+} / \mathrm{Ho}^{3+} / \mathrm{Eu}^{3+}$ from the NPs and the formation of the $\beta$ $\mathrm{NTA}-\mathrm{Tb}^{3+} / \mathrm{Ho}^{3+} / \mathrm{Eu}^{3+}-\mathrm{TOPO}$ complex enhancer solution and the digested solution were diluted and send to the ICPMS for final ${ }^{153} \mathrm{Eu} /{ }^{159} \mathrm{~Tb} /{ }^{165} \mathrm{Ho}$ quantification (Figure $1 \mathrm{~b}$ ). Because ICPMS exhibits accurate quantitative capacity and a wide detection range (Figure S1) for the three lanthanides we adopted, we can convert the amount of target according to signal strength.

Preparation of Viral RNA Extraction for Standard Recovery Experiment. The real sample matrix of three throat swab samples for the recovery experiment was collected 

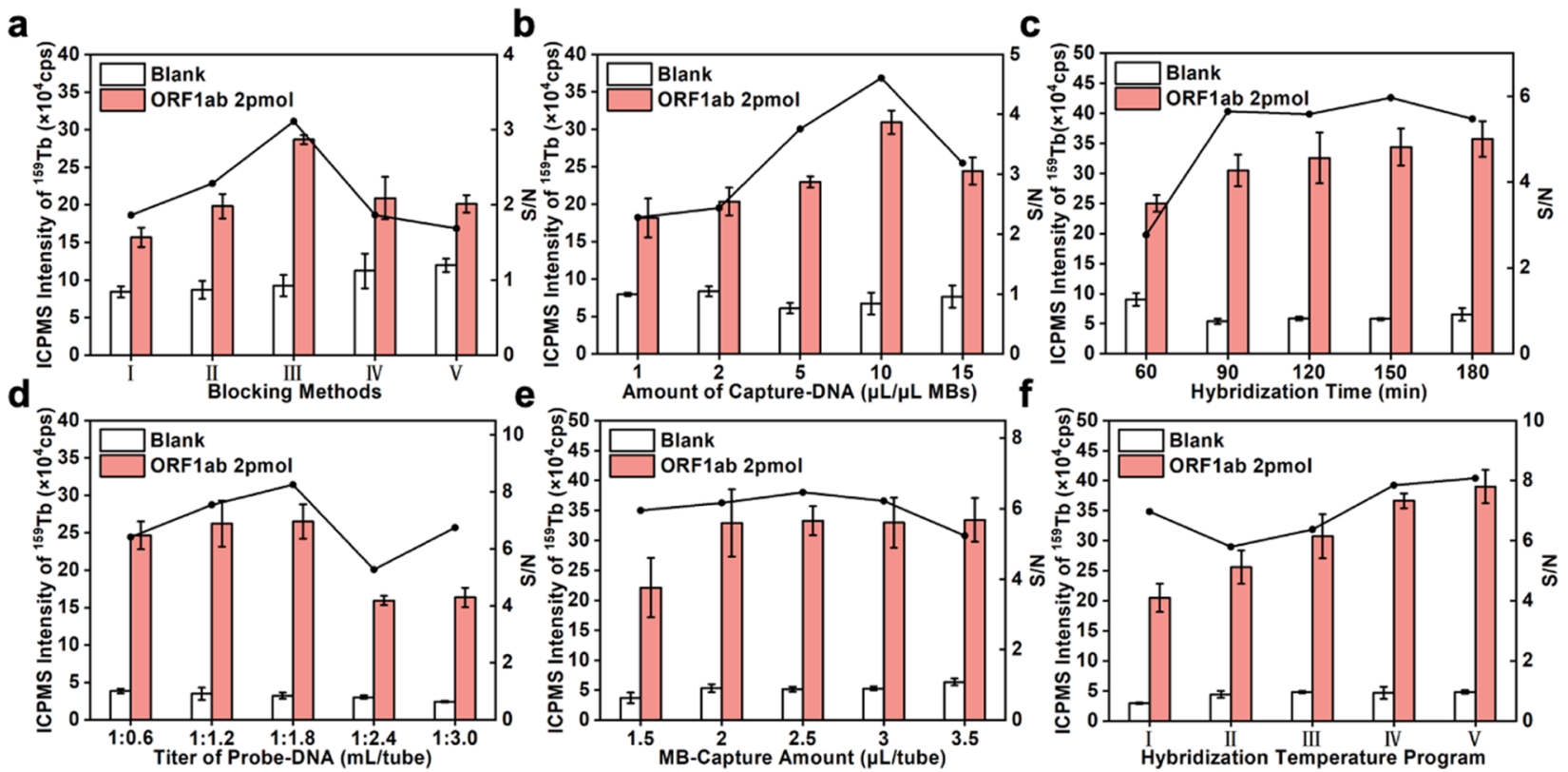

Figure 4. Optimization of reaction conditions (a) effects of different blocking methods: (I) $2 \%$ BSA, overnight. (II) $2 \%$ BSA, 1 h. (III) $2 \%$ BSA, 30 min. (IV) $2 \%$ BSA, wash. (V) $2 \%$ skim milk, 30 min. (b) Effects of the amount of capture-DNA added to MBs on the ICPMS intensity. (c) Effects of hybridization time on the ICPMS intensity. (d) Effects of titer for as-prepared probe-DNA, per tube, containing $60 \mu \mathrm{L}$ nanoparticles and $1 \mathrm{OD}$ DNA to a final volume of $1 \mathrm{~mL}$ and then diluted. (e) Effects of the as-prepared MB-capture amount per tube of a sample. (f) Effect of the hybridization temperature program: (I) $25^{\circ} \mathrm{C}, 150 \mathrm{~min}$. (II) $37^{\circ} \mathrm{C}, 150 \mathrm{~min}$. (III) $43^{\circ} \mathrm{C}, 90 \mathrm{~min}$, then $25^{\circ} \mathrm{C}, 60 \mathrm{~min}$. (IV) $43{ }^{\circ} \mathrm{C}, 120 \mathrm{~min}$ then $25{ }^{\circ} \mathrm{C}, 30 \mathrm{~min} .(\mathrm{V}) 43{ }^{\circ} \mathrm{C}, 150 \mathrm{~min}$.

using the RNA viral sample collection tubes and purified using the EZ-10 spin column viral total RNA extraction kit. Specific experimental steps are given in Supporting Information.

\section{RESULTS AND DISCUSSION}

Characterization of PAA-NaLnF 4 , Probe DNA-NaLnF 4 NPs, and the Capture DNA-MBs. Characterization of PAA-NaLnF 4 . Transmission electron microscopy (TEM) shows the spherical morphology of the $\mathrm{NaTbF}_{4}$ particles at about $100 \mathrm{~nm}$ (Figure 2a). It is worth noting that in these TEM figures, we can see the edges of the NPs have a slightly bright thin layer, which proves that the surface of the NPs is coated with PAA. The high-resolution TEM image (Figure 2b) shows lattice fringes with an observed $d$-spacing of $0.300 \mathrm{~nm}$, which is in good agreement with the lattice spacing in the (101) planes of hexagonal $\mathrm{NaTbF}_{4}$ (PDF \#27-0809). The Xray powder diffraction (XRD) patterns of the NPs exhibit peak position and intensities that can be well indexed in accord with $\mathrm{NaTbF}_{4}$ crystals (Figure S2a). Elements and corresponding proportions of a kind of particles by X-ray photoelectron spectroscopy (XPS) analysis give a peak area of $\mathrm{Na}, \mathrm{Tb}$, and $\mathrm{F}$ about 1:1:4 (Figure S3a). The one-step method also wraps the carboxyl group in the surface of the synthesis of the NPs, and the zeta potential of the naked NPs is positive. The NPs wrapped in the PAA encircled by the method exhibit negative electrical properties (Figure 2d). Similarly, in the Fourier transform infrared spectroscopy (FTIR), the PAA-modified NPs exhibit a carboxyl group characteristic peak compared to bare NPs (Figure 2f). Those of the other two NPs were similar, and detailed properties characterized by TEM and high resolution TEM (HRTEM) (Figures S4, S5), XRD and XPS (Figures S2, S3), zeta potential (Figure S6), and IR (Figure S8) are given in Supporting Information.

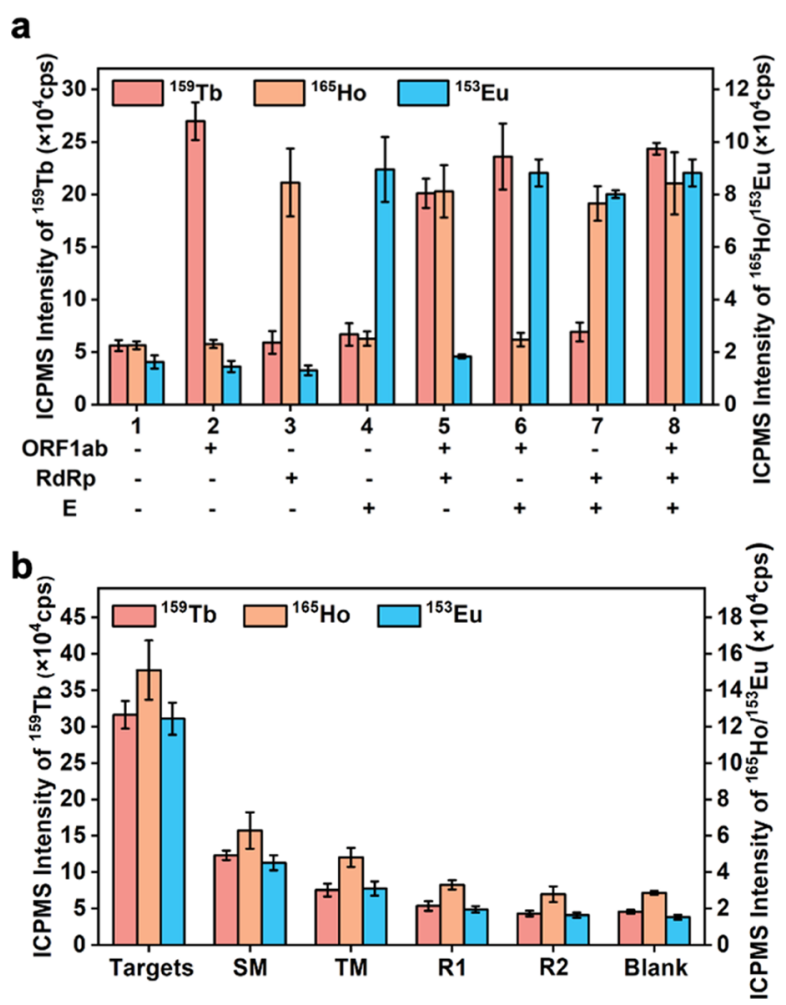

Figure 5. (a) Selectivity and cross-reactivity of the developed ICPMSbased multiple RNA fragment assay. (1) Blank, (2) ORF1ab, (3) RdRp, (4) E, (5) ORF1ab + RdRp, (6) ORFlab + E, (7) RdRp + ORF1ab, and (8) ORF $1 \mathrm{ab}+\mathrm{RdRp}+\mathrm{E}$. (b) Specificity of this method for the homologous sequences of ORFlab, RdRp, and E. "SM": single-mismatched targets and "TM": triple-mismatched targets. 
Table 1. Analytical Performance of ORF1ab/RdRp/E Based on ICPMS

\begin{tabular}{lclcc}
$\begin{array}{c}\text { target } \\
\text { RNA }\end{array}$ & $\begin{array}{c}\text { linear range } \\
(\mathrm{fmol})\end{array}$ & linear relationship & $R^{2}$ & $\begin{array}{c}\text { LOD } \\
(\mathrm{fmol})\end{array}$ \\
ORF1ab & $20-4000$ & $y=112,372 \lg x-11,479$ & 0.991 & 1.2 \\
RdRp & $20-4000$ & $y=26,165 \lg x-14,056$ & 0.991 & 1.3 \\
E & $20-4000$ & $y=29967 \lg x-24,277$ & 0.990 & 1.3 \\
\hline
\end{tabular}

Characterization of Probe DNA-NaLnF 4 NPs. Characterization of Probe DNA-NaLnF $4 \mathrm{NPs}_{4}$ is essential for our increased understanding of bioconjugation. This modification process can be characterized by multiple means. To understand the contents of the DNA attached to the nanoprobe we added for each sample, we used the high-resolution ICPMS (HR-ICPMS) to quantitatively analyze ${ }^{31} \mathrm{P}$ on the nanoprobes. ${ }^{51}$ We use the same length of DNA as used for a standard curve of the $\mathrm{P}$ element, then make a quantity of probe DNA (Figure 2c), and it is concluded that each sample substantially corresponds to $8 \mathrm{pmol}$ of probe added, with a similar connecting efficiency of each NP. The modification process was also validated by zeta potential with noticeable change (Figure 2d). In addition, dynamic light scattering (DLS) determined the increase of the particle size after DNA ligation. Characterization of the other NPs using zeta potential (Figure S6) and DLS (Figure S7) is given in Supporting Information.

Characterization of Capture DNA-MBs. The capture DNAMBs were prepared by coupling all three capture DNA with the same molar concentration onto SA-MBs in a one-pot process because it has similar analysis performance compared to separate coupling (Figure S9). In theory, each type of capture DNA strand accounted for one-third of the total attached capture DNA. Changes in zeta-potential (Figure S10a) and hydrodynamic size (Figure S10b) revealed
Table 2. Results of Standard Recovery Experiment in Virus RNA Extract

\begin{tabular}{|c|c|c|c|c|}
\hline sample & target RNA & added (fmol) & found (fmol) & recovery (\%) \\
\hline \multirow[t]{9}{*}{$1 \#$} & \multirow[t]{3}{*}{ ORF1ab } & 0 & not found & \\
\hline & & 200 & $181 \pm 11.6$ & 90 \\
\hline & & 2000 & $1848 \pm 177$ & 92 \\
\hline & \multirow[t]{3}{*}{ RdRp } & 0 & not found & \\
\hline & & 200 & $189 \pm 25.8$ & 94 \\
\hline & & 2000 & $2041 \pm 211$ & 102 \\
\hline & \multirow[t]{3}{*}{$\mathrm{E}$} & 0 & not found & \\
\hline & & 200 & $183 \pm 12.9$ & 92 \\
\hline & & 2000 & $2083 \pm 121$ & 104 \\
\hline \multirow[t]{9}{*}{$2 \#$} & \multirow[t]{3}{*}{ ORF1ab } & 0 & not found & \\
\hline & & 200 & $190 \pm 11.4$ & 95 \\
\hline & & 2000 & $1934 \pm 105$ & 97 \\
\hline & \multirow[t]{3}{*}{ RdRp } & 0 & not found & \\
\hline & & 200 & $213 \pm 43.4$ & 106 \\
\hline & & 2000 & $1928 \pm 118$ & 96 \\
\hline & \multirow[t]{3}{*}{$\mathrm{E}$} & 0 & not found & \\
\hline & & 200 & $191 \pm 10.7$ & 96 \\
\hline & & 2000 & $1958 \pm 49.0$ & 98 \\
\hline \multirow[t]{9}{*}{$3 \#$} & \multirow[t]{3}{*}{ ORF1ab } & 0 & not found & \\
\hline & & 200 & $224 \pm 17.9$ & 112 \\
\hline & & 2000 & $1855 \pm 68.4$ & 93 \\
\hline & \multirow[t]{3}{*}{ RdRp } & 0 & not found & \\
\hline & & 200 & $196 \pm 32.6$ & 98 \\
\hline & & 2000 & $1810 \pm 143$ & 91 \\
\hline & \multirow[t]{3}{*}{ E } & 0 & not found & \\
\hline & & 200 & $208 \pm 8.80$ & 104 \\
\hline & & 2000 & $1870 \pm 129$ & 94 \\
\hline
\end{tabular}

successful coupling outcomes. Our values also match the instructions of Dynabeads M280.

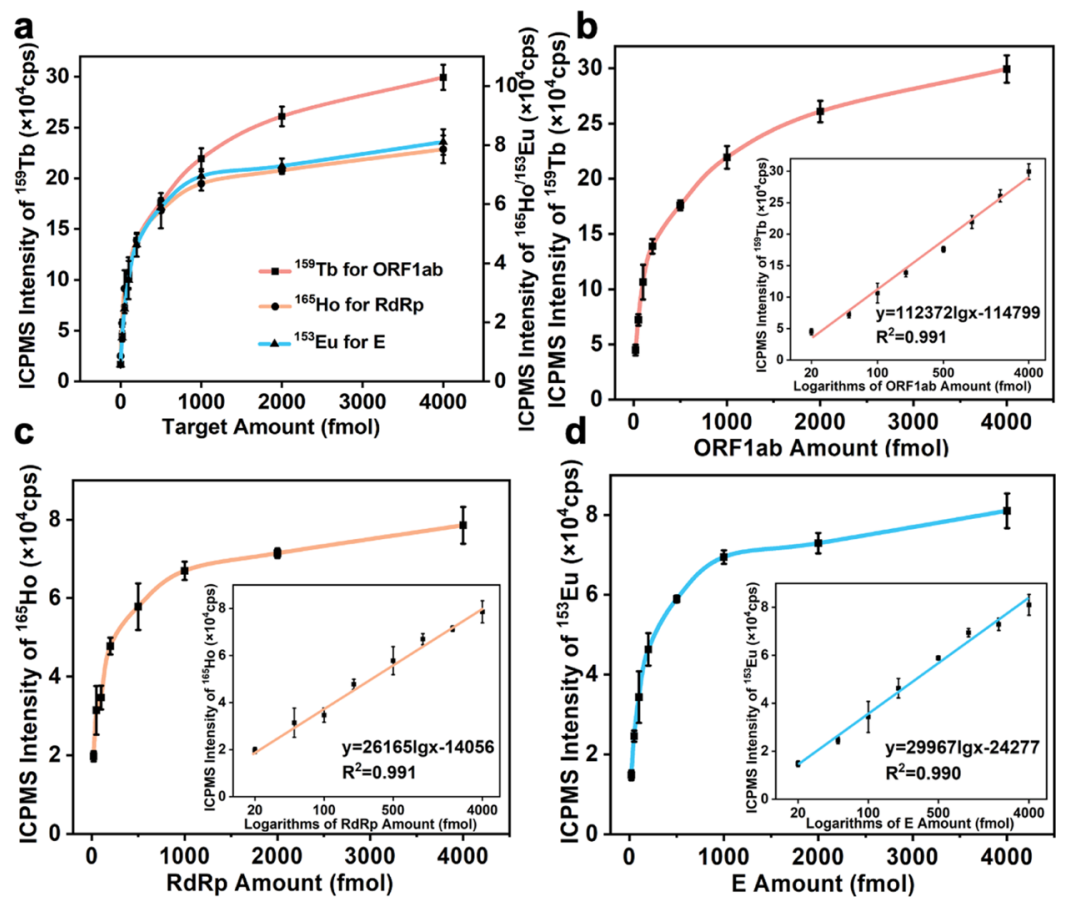

Figure 6. (a) Simultaneous detection of $\mathrm{ORF} 1 \mathrm{ab} / \mathrm{RdRp} / \mathrm{E}$ and relationship between the signal intensities of ${ }^{159} \mathrm{~Tb} /{ }^{165} \mathrm{Ho} /{ }^{153} \mathrm{Eu}$ and the concentrations of ORF1ab/RdRp/E. Linear range with the inset graph showing the calibration curves of (a) ORF1ab, (b) RdRp, and (c) E based on ICP-MS. 
Table 3. Summary of Three Detection Approaches Used in Detecting SARS-CoV-2 Nucleic Acid and Two Multiplexed Nucleic Acid Assay by ICPMS

\begin{tabular}{|c|c|c|c|c|c|}
\hline techniques & advantages & limitations & linear range & LOD & refs \\
\hline RT-qPCR & multiplexed Assay & spectral overlap & & 2 copies $/ \mu \mathrm{L}$ & 23 \\
\hline electrochemical sensors & rapid detection & unable multiplexed assay & & $26 \mathrm{fM}$ & 14 \\
\hline POCT & ultrafast and recyclable & unable multiplexed assay & & $0.843 \mathrm{nM}$ & 18 \\
\hline element tagging ICPMS assay & multiplexed Assay & narrow detection range & $0.84-20 \mathrm{pmol}$ & $0.84 \mathrm{pmol}$ & 41 \\
\hline DSN amplification ICPMS assay & multiplexed Assay & low sensitivity & $58-200 \mathrm{fmol}$ & $48 \mathrm{fmol}$ & 48 \\
\hline
\end{tabular}

Feasibility of the Sandwich Assay-ICPMS Strategy. To test the feasibility of the developed multiplex SARS-CoV-2 RNA fragment assay, ICPMS detection under different conditions was done (Figure S11). Another more intuitive evidence is that under TEM, it shows naked MBs without immobilization in Figure 3a. After hybridization, three kinds of NPs were attached. Several $\mathrm{NaTbF}_{4}, \mathrm{NaHoF}_{4}$, and $\mathrm{NaEuF}_{4}$ could be observed clearly (Figure $3 \mathrm{~b}$ ). A similar phenomenon could also be observed in the SEM image (Figure S12) with its inset graph giving the compositional analysis by energydispersive X-ray spectroscopy (EDS). There emerged elemental peaks of $\mathrm{Tb}, \mathrm{Ho}$, and $\mathrm{Eu}$ in the EDS diagram, and small particles could be found on MBs (Figure 3c). The above evidence demonstrated successful hybridization, and a sandwich structure was formed. To further prove this strategy's feasibility, five artificial samples containing different concentrations of ORF1ab, RdRp, and $\mathrm{E}$ were prepared and hybridized with capture O/R/E-MBs and O/R/E-Tb/Ho/Eu NPs. With the increase in ORFlab, RdRp, and $\mathrm{E}$ concentrations, the signal intensities of ${ }^{159} \mathrm{~Tb},{ }^{165} \mathrm{Ho}$, and ${ }^{153} \mathrm{Eu}$ also increased (Figure $3 \mathrm{~d}$ ).

Optimization of Experimental Conditions. Experimentally, one of the RNA fragments, ORFlab with the corresponding tagging $\mathrm{NP} \mathrm{NaTbF}_{4}$, was chosen as the model RNA for optimizing experimental conditions. It has a similar length to the other two components of the test object, so the corresponding characteristics such as Tm are similar. Based on this, various experimental parameters were optimized using blocking methods, reaction time and temperature, and the number of components of this system (capture DNA, capture$\mathrm{MB}$, and probe-DNA). The specific details about the reaction are given in Supporting Information.

Effects of Different Blocking Methods. NPs will have nonspecific adsorption of some molecules due to their nanoscale effects. We use proteins to block the remaining sites of the NPs that have been bound to DNA that may be nonspecifically adsorbed. Figure $4 \mathrm{a}$ reveals that there has been a steep decline in the signal when the blocking condition is not suitable for this system. The blocking condition we finally selected is $2 \% \mathrm{BSA}, 30 \mathrm{~min}$.

Effects of the Amount of Capture-DNA Added to MBs. In a further set of experiments, we explored the reaction ratio of MBs to captured DNA (Figure 4b). According to the binding capacity instructions of the MBs, we have selected a range of DNA concentrations to achieve the maximum binding efficiency and at the same time to ensure that DNA addition is not too excessive to cause insufficient washing in which free DNA might lead to interference on subsequent sandwich hybridization reactions. Finally, the condition we selected is the group with the highest signal-to-noise ratio, that is, when the concentration of capture DNA is $2 \mu \mathrm{M}$, the volume ratio of DNA to MBs is $10: 1$.
Effects of Hybridization Time. Hybridization time is a common condition that has a considerable impact on reaction efficiency. To guarantee enough time and control nonspecific adsorption, we explored the reaction efficiency in the time range of $60-180 \mathrm{~min}$, as shown in Figure 4c. Taking signal growth and blank control as dual considerations, as time grows, the signal value first shows an upward trend and then gradually stabilizes, while the blank value first decreases due to the competition of the target molecule and then increases due to time. Considering the signal-to-noise ratio, we choose $150 \mathrm{~min}$ as the best hybridization time.

Effects of the Titer for As-prepared Probe-DNA. What can be seen in Figure $4 \mathrm{~d}$ is the influence of probes of different titers on the experimental results. For $60 \mu \mathrm{L}$ NPs and 1OD DNA per tube; the corresponding condition is the diluted volume of each probe, ranging from 0.6 to $3.0 \mathrm{~mL}$. From the changing trend of the signal and blank value in the figure, when the probe is more concentrated and the titer is relatively low, the NPs on the excess probe will produce more nonspecific adsorption on the reaction substrate. As the temperature increases, the blank gradually decreases, but if the probe is too dilute, the concentration of probe DNA used to bind the target will decrease, and the reaction speed and efficiency will subside, too, making it impossible to obtain high signal values. Taking these effects into consideration, we assumed that the titer 1 to $1.8 \mathrm{~mL}$ with the highest signal-to-noise ratio was selected for applying under subsequent experimental conditions.

Effects of the As-prepared MB-Capture Amount. As the unit of the sandwich structure, MB-capture and Probe-DNA have similar influence trends on the reaction. Under the premise of ensuring the amount for reaction, as a reaction matrix, the increase of MBs is positively correlated with the increase in nonspecific adsorption (Figure 4e). Therefore, we choose a moderate amount, $2.5 \mu \mathrm{L}$ per sample, and perform subsequent reactions under this condition.

Effect of the Hybridization Temperature Program. We studied the appropriate time for the interaction. Under the same reaction time, when the selected reaction temperature is below the melting temperature $\left(T_{\mathrm{m}}\right)$ of $15-20^{\circ} \mathrm{C}$ of the target sequence, the reaction would be more efficient; the lower the temperature, the more stable the double-stranded binding DNA. To explore the checks and balances of these two factors, we have designed a series of hybridization temperature programs as shown in Figure 4f. When the temperature is 43 ${ }^{\circ} \mathrm{C}$, the best signal-to-noise ratio can be obtained. Finally, 43 ${ }^{\circ} \mathrm{C}$ was chosen as the optimum reaction temperature.

Specificity and Selectivity. When multiple components are the target to be analyzed, it is necessary to ensure that there will be no mutual influence between them. We experimentally prove the mechanism of this strategy and demonstrate its specificity. We have prepared a series of target gene fragment solutions with different components, as shown in Figure 5a. 
According to the signal intensity of lanthanide metal ions corresponding to different target combinations in the histogram, we can see those signals of ${ }^{159} \mathrm{~Tb} /{ }^{165} \mathrm{Ho} /{ }^{153} \mathrm{Eu}$ upon the addition of corresponding RNAs were much higher than their blank signals; whether it is a single component or a mixture of any two components, even the three components are tested together, it shows independent and steady results demonstrating reasonable specificity of the method.

Similarly, there may be a variety of nontarget nucleic acid fragments in real samples. Due to the high sequence homology of RNA, we detected a series of sequences similar to the three targets to prove the selectivity of the established strategy. The results are shown in Figure 5b. Experimental groups were containing single-mismatched RNA fragments and triplemismatched RNA fragments of both ORF1ab/RdRp/E. What is more, random RNA and random DNA were also detected, and the results were similar to those of blank groups, indicating a decent selectivity.

Analytical Performance. After optimizing a series of reaction conditions, we explored the analytical performance of the established analytical method as listed in Table 1 . In the simultaneous detection strategy, the calibration curves were built up with varieties of RNA fragment (ORF1ab, RdRp, and E) concentrations $(0,20,50,100,200,500,1000,2000$, and 4000) and ICPMS signal intensities of lanthanide elements $\left({ }^{159} \mathrm{~Tb} /{ }^{165} \mathrm{Ho} /{ }^{153} \mathrm{Eu}\right)$. As shown in Figure $6 \mathrm{a}$, the three targets can be mixed and quantified and have similar growth trends. In the inset figures of Figure $6 b-d$, after we perform logarithmic processing and linear fitting of the data, decent linear relationships were obtained at 20-4000 fmol for ORF1ab, $\mathrm{RdRp}$, and $\mathrm{E}$ with equations $y=112,372 \lg x-11,479, y=$ $112,372 \lg x-11,479$, and $y=29,967 \lg x-24,277$. The limits of detection ( $3 \sigma / k$, LODs) for ORF1ab, RdRp, and E were $1.2,1.3$, and $1.3 \mathrm{fmol}$, respectively.

For investigating the self-magnification of this strategy, the analytical performance was compared with those of other multicomponent simultaneous analysis methods by ICPMS. We use lanthanide NPs as element markers. Compared with the traditional macrocyclic compound-lanthanide element tagging, it has a more comprehensive linear range and three orders of magnitude higher sensitivity; compared with the DSN amplification strategy, the LOD was decreased by 40 -fold (Table 3). This shows that even working with the simplest sandwich hybrid structure, our strategy can achieve higher sensitivity and high multiplicity without additional amplification reactions.

Recoveries and Determined Results. Healthy human throat swab samples were collected, purified, collected, spiked, and analyzed to evaluate the method's applicability. To investigate the influence of the matrix, three target RNAs numbered as 1\#, 2\#, and 3\# were spiked in RNA extraction solution simultaneously at the concentrations of 0,200 , and 2000 fmol. Moreover, the spiked samples were subjected to the proposed method. Quantitative recovery outcomes are all listed in Table 2. As shown, $181 \mathrm{fmol}$ of ORF1ab,189 fmol of RdRp, and 183 fmol of E were simultaneously found. The recoveries of 90, 94, and 92\% were gained when 200 fmol RNA was added and extracted in the $1 \#$ throat swab sample. The spiked recovery results of other matrix samples at different concentrations are also within the range of $90-112 \%$. Thus, it has added robust evidence for tolerance of the RNA virus extraction sample matrix and showed prospects of this strategy for the actual application of the experiments.

\section{CONCLUSIONS}

In this work, we have established a multiplexed sandwich RNA analytical method based on NP self-enhanced RNA analysis to detect three specific RNA gene sites of SARS-CoV-2 simultaneously. Three lanthanide NP probes synthesized by the one-step solvent thermal method are modified by a carboxyl group and further coupled with DNA to perform signal report units. Meanwhile, with the chelating ability of $\beta$ NTA and the magnetic properties of SA-MBs, the lanthanide tag as the multiplexed probe can be quickly released in the form of ions to form a uniform solution. Thus, high-sensitivity detection can be realized through the self-amplification of NPs. If other nucleic acid amplification strategies are introduced into the system, the sensitivity can be further improved. We expect that this detection platform can increase the detection rate of SARS-CoV-2 through the simultaneous detection of multiple genes, and this strategy can be extended to the sensitive simultaneous detection of other nucleic acids or biomarkers.

\section{ASSOCIATED CONTENT}

\section{(5) Supporting Information}

The Supporting Information is available free of charge at https://pubs.acs.org/doi/10.1021/acs.analchem.1c02657.

Experimental details including the apparatus, materials, and reagents used; synthesis of NPs; preparation of probes; recovery RNA samples; characterization of NPs using XPS, XRD, SEM, TEM and HRTEM, FTIR, and size and zeta potential of the probe; operating parameters of ICP-MS and DNA sequences (PDF)

\section{AUTHOR INFORMATION}

\section{Corresponding Authors}

Rui Liu - Key Laboratory of Green Chemistry \& Technology, Ministry of Education, College of Chemistry, Sichuan University, Chengdu 610064 Sichuan, China; (1) orcid.org/ 0000-0001-9928-5373; Phone: +86-28-8541-2398; Email: liur@scu.edu.cn; Fax: +86-28-8541-2398

Yi Lv - Analytical \& Testing Center, Sichuan University, Chengdu 610064 Sichuan, China; (1) orcid.org/0000-00027104-2414; Email: lvy@scu.edu.cn

\section{Authors}

Ziyan Li - Analytical \& Testing Center, Sichuan University, Chengdu 610064 Sichuan, China

Xue Chen - Key Laboratory of Green Chemistry \& Technology, Ministry of Education, College of Chemistry, Sichuan University, Chengdu 610064 Sichuan, China

Zili Huang - Key Laboratory of Green Chemistry \& Technology, Ministry of Education, College of Chemistry, Sichuan University, Chengdu 610064 Sichuan, China

Jing Zhou - Analytical \& Testing Center, Sichuan University, Chengdu 610064 Sichuan, China

Complete contact information is available at: https://pubs.acs.org/10.1021/acs.analchem.1c02657

\section{Notes}

The authors declare no competing financial interest.

\section{ACKNOWLEDGMENTS}

We gratefully acknowledged the National Natural Science Foundation of China (no. 22074098 and 22074096), the Talents Program of Sichuan Province (no. 903), Sichuan 
Science and Technology Program (19YYJC2423), and the Fundamental Research Funds for the Central Universities. In addition, Dr. Yingying Su from Analytical and Testing Center and Dr. Chunxia Wang from College of Chemistry, Sichuan University, are thanked for the helpful discussion/technical assistance.

\section{REFERENCES}

(1) Zhu, N.; Zhang, D.; Wang, W.; Li, X.; Yang, B.; Song, J.; Zhao, X.; Huang, B.; Shi, W.; Lu, R.; Niu, P.; Zhan, F.; Ma, X.; Wang, D.; Xu, W.; Wu, G.; Gao, G. F.; Tan, W.; China Novel Coronavirus, I.; Research, T. N. Engl. J. Med. 2020, 382, 727-733.

(2) Guan, W.-j.; Ni, Z.-y.; Hu, Y.; Liang, W.-h.; Ou, C.-q.; He, J.-x.; Liu, L.; Shan, H.; Lei, C.-1.; Hui, D. S. C.; Du, B.; Li, L.-j.; Zeng, G.; Yuen, K.-Y.; Chen, R.-c.; Tang, C.-1.; Wang, T.; Chen, P.-y.; Xiang, J.; Li, S.-y.; Wang, J.-1.; Liang, Z.-j.; Peng, Y.-x.; Wei, L.; Liu, Y.; Hu, Y.h.; Peng, P.; Wang, J.-m.; Liu, J.-y.; Chen, Z.; Li, G.; Zheng, Z.-j.; Qiu, S.-q.; Luo, J.; Ye, C.-j.; Zhu, S.-y.; Zhong, N.-s. N. Engl. J. Med. 2020, 382, 1708-1720.

(3) Poh, C. M.; Carissimo, G.; Wang, B.; Amrun, S. N.; Lee, C. Y.P.; Chee, R. S.-L.; Fong, S.-W.; Yeo, N. K.-W.; Lee, W.-H.; TorresRuesta, A.; Leo, Y.-S.; Chen, M. I.-C.; Tan, S.-Y.; Chai, L. Y. A.; Kalimuddin, S.; Kheng, S. S. G.; Thien, S.-Y.; Young, B. E.; Lye, D. C.; Hanson, B. J.; Wang, C.-I.; Renia, L.; Ng, L. F. P. Nat. Commun. 2020, 11, 2806.

(4) Ng, D. L.; Goldgof, G. M.; Shy, B. R.; Levine, A. G.; Balcerek, J.; Bapat, S. P.; Prostko, J.; Rodgers, M.; Coller, K.; Pearce, S.; Franz, S.; Du, L.; Stone, M.; Pillai, S. K.; Sotomayor-Gonzalez, A.; Servellita, V.; Martin, C. S. S.; Granados, A.; Glasner, D. R.; Han, L. M.; Truong, K.; Akagi, N.; Nguyen, D. N.; Neumann, N. M.; Qazi, D.; Hsu, E.; Gu, W.; Santos, Y. A.; Custer, B.; Green, V.; Williamson, P.; Hills, N. K.; Lu, C. M.; Whitman, J. D.; Stramer, S. L.; Wang, C.; Reyes, K.; Hakim, J. M. C.; Sujishi, K.; Alazzeh, F.; Pham, L.; Thornborrow, E.; Oon, C.-Y.; Miller, S.; Kurtz, T.; Simmons, G.; Hackett, J., Jr.; Busch, M. P.; Chiu, C. Y. Nat. Commun. 2020, 11, 4698.

(5) Zhao, J.; Yuan, Q.; Wang, H.; Liu, W.; Liao, X.; Su, Y.; Wang, X.; Yuan, J.; Li, T.; Li, J.; Qian, S.; Hong, C.; Wang, F.; Liu, Y.; Wang, Z.; He, Q.; Li, Z.; He, B.; Zhang, T.; Fu, Y.; Ge, S.; Liu, L.; Zhang, J.; Xia, N.; Zhang, Z. Clin. Infect. Dis. 2020, 71, 2027-2034.

(6) Xiong, H.; Ye, X.; Li, Y.; Wang, L.; Zhang, J.; Fang, X.; Kong, J. Anal. Chem. 2020, 92, 14297-14302.

(7) Smyrlaki, I.; Ekman, M.; Lentini, A.; Rufino de Sousa, N.; Papanicolaou, N.; Vondracek, M.; Aarum, J.; Safari, H.; Muradrasoli, S.; Rothfuchs, A. G.; Albert, J.; Högberg, B.; Reinius, B. Nat. Commun. 2020, 11, 4812.

(8) West, C. P.; Montori, V. M.; Sampathkumar, P. Mayo Clin. Proc. 2020, 95, 1127-1129.

(9) Kinloch, N. N.; Ritchie, G.; Brumme, C. J.; Dong, W.; Dong, W.; Lawson, T.; Jones, R. B.; Montaner, J. S. G.; Leung, V.; Romney, M. G.; Stefanovic, A.; Matic, N.; Lowe, C. F.; Brumme, Z. L. J. Infect. Dis. 2020, 222, 899-902.

(10) Wiersinga, W. J.; Rhodes, A.; Cheng, A. C.; Peacock, S. J.; Prescott, H. C. JAMA 2020, 324, 782-793.

(11) National Health Commission of the People's Republic of China and Traditional Chinese Medicine of the People's Republic of China (2020) Guidelines for the Diagnosis and Treatment of Coronavirus Disease 2019 (Trial Version 7).

(12) CDC. CDC 2019-Novel Coronavirus (2019-nCoV) Real-Time RT-PCR Diagnostic Panel SOP\# CDC-006-00019, 2020.

(13) CDC. CDC 2019-nCoV Real-Time RT-PCR Diagnostic Panel Product Information Sheet SOP\# CDC-006-00006, 2020.

(14) Peng, Y.; Pan, Y.; Sun, Z.; Li, J.; Yi, Y.; Yang, J.; Li, G. Biosens. Bioelectron. 2021, 186, 113309.

(15) Karami, A.; Hasani, M.; Azizi Jalilian, F.; Ezati, R. Sens. Actuators B Chem. 2021, 328, 128971.

(16) Arizti-Sanz, J.; Freije, C. A.; Stanton, A. C.; Petros, B. A.; Boehm, C. K.; Siddiqui, S.; Shaw, B. M.; Adams, G.; KosokoThoroddsen, T.-S. F.; Kemball, M. E.; Uwanibe, J. N.; Ajogbasile, F.
V.; Eromon, P. E.; Gross, R.; Wronka, L.; Caviness, K.; Hensley, L. E.; Bergman, N. H.; MacInnis, B. L.; Happi, C. T.; Lemieux, J. E.; Sabeti, P. C.; Myhrvold, C. Nat. Commun. 2020, 11, 5921.

(17) Feng, W.; Newbigging, A. M.; Tao, J.; Cao, Y.; Peng, H.; Le, C.; Wu, J.; Pang, B.; Li, J.; Tyrrell, D. L.; Zhang, H.; Le, X. C. Chem. Sci. 2021, 12, 4683-4698.

(18) Hwang, C.; Park, N.; Kim, E. S.; Kim, M.; Kim, S. D.; Park, S.; Kim, N. Y.; Kim, J. H. Biosens. Bioelectron. 2021, 185, 113177.

(19) Sargsyan, K.; Lin, C.-C.; Chen, T.; Grauffel, C.; Chen, Y.-P.; Yang, W.-Z.; Yuan, H. S.; Lim, C. Chem. Sci. 2020, 11, 9904-9909.

(20) Vidal-Folch, N.; Gavrilov, D.; Raymond, K.; Rinaldo, P.; Tortorelli, S.; Matern, D.; Oglesbee, D. Clin. Chem. 2018, 64, 17531761.

(21) Jacky, L.; Yurk, D.; Alvarado, J.; Belitz, P.; Fathe, K.; MacDonald, C.; Fraser, S.; Rajagopal, A. Anal. Chem. 2021, 93, $4208-4216$

(22) Kudo, E.; Israelow, B.; Vogels, C. B. F.; Lu, P.; Wyllie, A. L.; Tokuyama, M.; Venkataraman, A.; Brackney, D. E.; Ott, I. M.; Petrone, M. E.; Earnest, R.; Lapidus, S.; Muenker, M. C.; Moore, A. J.; Casanovas-Massana, A.; Yale, I. R. T.; Omer, S. B.; Dela Cruz, C. S.; Farhadian, S. F.; Ko, A. I.; Grubaugh, N. D.; Iwasaki, A. PLoS Biol. 2020, 18, No. e3000867.

(23) Byrnes, S. A.; Gallagher, R.; Steadman, A.; Bennett, C.; Rivera, R.; Ortega, C.; Motley, S. T.; Jain, P.; Weigl, B. H.; Connelly, J. T. Anal. Chem. 2021, 93, 4160-4165.

(24) Alygizakis, N.; Markou, A. N.; Rousis, N. I.; Galani, A.; Avgeris, M.; Adamopoulos, P. G.; Scorilas, A.; Lianidou, E. S.; Paraskevis, D.; Tsiodras, S.; Tsakris, A.; Dimopoulos, M.-A.; Thomaidis, N. S. Trends Anal. Chem. 2021, 134, 116125.

(25) Mou, X.-B.; Ali, Z.; Li, B.; Li, T.-T.; Yi, H.; Dong, H.-M.; He, N.-Y.; Deng, Y.; Zeng, X. Chin. Chem. Lett. 2016, 27, 1661-1665.

(26) Liu, R.; Wu, P.; Yang, L.; Hou, X.; Lv, Y. Mass Spectrom. Rev. 2014, 33, 373-393.

(27) Lin, X.; Guo, W. J.; Jin, L.; Hu, S. At. Spectrosc. 2020, 41, 1-10.

(28) Liu, J.; Zheng, L.; Shi, J.; Wei, X.; Li, X.; Chen, M.; Wang, M.; Wang, J.; Feng, W. At. Spectrosc. 2021, 42, 114-119.

(29) Bendall, S. C.; Nolan, G. P.; Roederer, M.; Chattopadhyay, P. K. Trends Immunol. 2012, 33, 323-332.

(30) Bodenmiller, B.; Zunder, E. R.; Finck, R.; Chen, T. J.; Savig, E. S.; Bruggner, R. V.; Simonds, E. F.; Bendall, S. C.; Sachs, K.; Krutzik, P. O.; Nolan, G. P. Nat. Biotechnol. 2012, 30, 858-867.

(31) Winter, D. R.; Ledergor, G.; Amit, I. Nat. Biotechnol. 2015, 33, 931-932.

(32) Winge, R. K.; Peterson, V. J.; Fassel, V. A. Appl. Spectrosc. 1979, 33, 206-219.

(33) Liu, X.; Zhang, S.-Q.; Cheng, Z.-H.; Wei, X.; Yang, T.; Yu, Y.L.; Chen, M.-L.; Wang, J.-H. Anal. Chem. 2018, 90, 12116-12122.

(34) Yan, X.; Yang, L.; Wang, Q. Anal. Bioanal. Chem. 2013, 405, 5663-5670.

(35) Liu, Z.; Li, X.; Xiao, G.; Chen, B.; He, M.; Hu, B. Trends Anal. Chem. 2017, 93, 78-101.

(36) Liang, Y.; Yang, L.; Wang, Q. Appl. Spectrosc. Rev. 2015, 51, $117-128$.

(37) Zhang, X.-W.; Liu, M.-X.; He, M.-Q.; Chen, S.; Yu, Y.-L.; Wang, J.-H. Anal. Chem. 2021, 93, 6437-6445.

(38) Cohen, L.; Walt, D. R. Chem. Rev. 2019, 119, 293-321.

(39) Li, Z.; Liu, R.; Lv, Y. Appl. Spectrosc. Rev. 2021, 1-26.

(40) Jet, T.; Gines, G.; Rondelez, Y.; Taly, V. Chem. Soc. Rev. 2021 50, 4141-4161.

(41) Han, G.; Zhang, S.; Xing, Z.; Zhang, X. Angew. Chem., Int. Ed. 2013, 52, 1466-1471.

(42) Sun, G.; Huang, B.; Zhang, Y.; Zhang, Y.; Xing, Z.; Zhang, S.; Zhang, X. Chem. Commun. 2017, 53, 13075-13078.

(43) Yan, X.; Yang, L.; Wang, Q. Angew. Chem., Int. Ed. Engl. 2011, $50,5130-5133$.

(44) Kang, Q.; He, M.; Chen, B.; Xiao, G.; Hu, B. Anal. Chem. 2021, 93, 737-744.

(45) Zhang, S.; Han, G.; Xing, Z.; Zhang, S.; Zhang, X. Anal. Chem. 2014, 86, 3541-3547. 
(46) Li, Z.; Li, H.; Deng, D.; Liu, R.; Lv, Y. Anal. Chem. 2020, 92, $4807-4813$

(47) Guo, H.; Song, X.; Lei, W.; He, C.; You, W.; Lin, Q.; Zhou, S.; Chen, X.; Chen, Z. Angew. Chem., Int. Ed. Engl. 2019, 58, 1219512199.

(48) Zhang, S.; Liu, R.; Xing, Z.; Zhang, S.; Zhang, X. Chem. Commun. 2016, 52, 14310-14313.

(49) Liu, R.; Zhang, S.; Wei, C.; Xing, Z.; Zhang, S.; Zhang, X. Acc. Chem. Res. 2016, 49, 775-783.

(50) Huang, W.; Ji, M.; Dong, C.-D.; Gu, X.; Wang, L.-M.; Gong, X. G.; Wang, L.-S. ACS Nano 2008, 2, 897-904.

(51) Hu, J.; Li, Z.; Zhang, H.; Liu, R.; Lv, Y. Anal. Chem. 2020, 92, $8523-8529$. 